\section{Five Years of PJP}

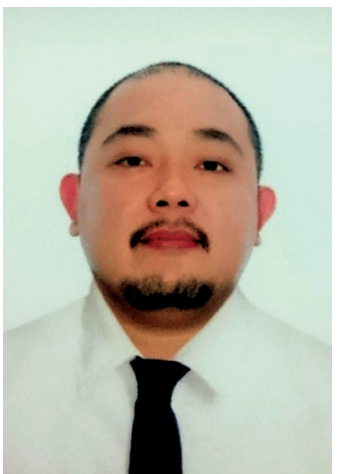

Quietly, while the world rages with the pandemic of our lifetime, the Philippine Journal of Pathology (PJP) celebrated its fifth year of publication. I find it appropriate to pause for a while and ask "what have we achieved over the past five years?"

First, we were able to professionalize the operations of the journal, through editorial guidelines at par with international standards of ethical publication, operating procedures that standardized the process of submission, peer review, and publication, and a virtual office and secretariat hired by the Society to man the day-to-day tasks of the journal.

Second, we have attained a sense of sustainability, and this is through the financial support of the Philippine Society of Pathologists (PSP). We are fortunate, for the leadership of the Society over the last five years have seen and continues to see the academic value of the journal. The Society's support extended beyond finances, as, over time, we have been able to engage more pathologists to share their time and expertise to peer review for the journal. These are invaluable inputs to our pursuit of academic excellence and scholarship, as peer review is the backbone of our publication.

Third, efforts to improve visibility, and accessibility are starting to pay off. CrossRef digital object identifiers ensured link permanence, improved searchability, and directed traffic to our journal website. We have been included in the ASEAN Citation Index. Our articles from 2016 to present are now searchable in the web. Some of our articles have also been cited by other researchers. This can only be possible if our articles can be "found" in the depths of the world wide web. Try looking for an article published in PJP in Google Scholar and you will find it. Moreover, our decision to go open access has translated to views and downloads of our manuscripts. Our statistics are modest, but over time, I predict that we will see better numbers in terms of views and citations. The dream of having our own "impact factor" may not be too farfetched after all.

Fourth, by publishing continuously and regularly for the last five years, we have somehow uplifted the research and publication awareness of our pathologists. Again, this is not an easy thing to do, from the conception and completion of the research, to the analysis and manuscript writing, and finally to hurdling the peer review and coming back with acceptable revisions. At the end of it, I am happy to see our younger pathologists proudly including publication in our journal as some form of academic accomplishment and sharing them in social media.

Fifth, as a Society, we have successfully relaunched an online journal management platform that made issues predictable, that is to say, regularly came out as scheduled every six months. This is no easy feat. One of the greatest challenges for local journals, based from shared experiences with other editors, is regularity and frequency. This is the reason why some local medical journals fail to come out with issues after some time and would need to be resuscitated and resurrected after several years in hiatus.

As a form of "paying it forward," I was offered to be an editorial consultant for the rebirth of the Scientific Proceedings of the Lung Center of the Philippines. Guided by the experiences I have gained from an international publication, which we used to reestablish the PJP, we guided them in turn. In a few months working with their dedicated and motivated editorial team, the journal was successfully relaunched this December. By providing this assistance, we are also advocating the Society's commitment to ethical standards of publication. It makes me proud when non-pathologists are impressed by the PJP and use it to improve their own publication.

Let me end this by thanking our authors, our reviewers, our readers, and the Society. For 2022 and beyond, we not only hope to continue, but we shall also aim to be included in the Directory of Open Access Journals, and WHO Western Pacific Region Index Medicus. We hope to increase the number of our articles and contribute to improvements in the practice of pathology in the country.

\section{Amado O. Tandoc III, MD, FPSP}

\section{Editor-in-Chief}

https://doi.org/10.21141/PJP.2021.20 